\title{
Valproic Acid Producing a Reye-Like Syndrome
}

\author{
D. L. KEENE, P. HUMPHREYS, B. CARPENTER, AND J.P. FLETCHER
}

SUMMARY: Although several cases of acute hepatic failure associated with the administration of valproic acid (VPA) have been reported, the pathogenesis of this problem remains unclear. We report the case of a 40 month old male with a chronic seizure disorder treated with VPA and phenytoin for two years, who developed sudden progressive neurological deterioration with evidence of increased intracranial pressure and hepatic failure. The clinical features closely resembled those of Reye's syndrome suggesting the possibility of a common pathogenesis.

RÉSUMÉ: Même s'il y a eu plusieurs cas d'insuffisance hépatique aigüe rapportés après l'administration d'acide valproique (VPA), nous ne comprenons pas encore la pathogénèse de ce problème. Nous rapportons le cas d'un mâle de 40 mois atteint d'un désordre épileptique chronique et qui fut traité avec VPA et phenytoin pendant 2 ans avant de développer une détérioration neurologie progressive et soudaine avec évidence d'augmentation de la pression intracrânienne et insuffisance hépato-rénale. L'aspect clinique ressemble de près à celui du syndrome de Reye et suggère la possibilité d'une pathogénèse commune.

From the Children's Hospital of Eastern Ontario, Ottawa, Ontario.

Requests for reprints to: Dr. D. L. Keene, Division of Neurology, Children's Hospital of Eastern Ontario, 401 Smyth Road, Ottawa, Ontario, K1 H $8 \mathrm{~L} 1$.

Presented in part at the XVI Canadian Congress of Neurological Sciences, Calgary, 1981.
Valproic acid (VPA) has been used as an anticonvulsant drug for the last 15 years in Europe and the last 5 years in North America. It has proved to be an effective drug in the treatment of generalized seizure disorders, and, to a lesser extent, the partial seizure disorders. Originally, the drug was felt to have few, if any, major side effects. With the passage of time, however, rare but serious side effects have been reported (i.e. thrombocytopenia, pancreatitis, hepatic dysfunction, coma). The purpose of this paper is to report a case of acute hepatic dysfunction associated with VPA usage with many similarities to Reye's syndrome. We present a brief literature review of the hepatic complications of VPA use, suggesting possible mechanisms of VPArelated hepatic decompensation. In light of this information some recommendations are made concerning VPA usage.

\section{CASE REPORT}

A 40 month old mentally retarded male with a severe refractory multifocal seizure disorder (onset 51/2 months of age) was readmitted to the Children's Hospital of Eastern Ontario in generalized tonic-clonic convulsive status. Adequate seizure control had never been achieved despite therapeutic serum levels of various anticonvulsant medications in several different combinations, including carbamazepine, primidone, ethosuximide, phenytoin (DPH) and valproic acid. A ketogenic diet had also been attempted without success. Frequent admissions to hospital had occurred over a two year period, usually for intractable generalized convulsive status. At the time of his final admission he was being treated with DPH, ethosuximide and valproic acid. VPA had been used for two years prior to the admission. Serum glutamic oxaloacetic transaminase (SGOT) levels had been normal for age until two weeks prior to admission at which time the level was twice normal range for age (i.e. greater than 30 I.U.) The VPA dosage was consequently decreased to half its previous value, following which the child developed generalized status prompting admission.

Shortly before the onset of this seizure activity the patient was noted to have a low grade fever and loose, foul smelling stools. After $1 \frac{1 / 2}{2}$ hours of almost continuous generalized tonicclonic convulsive status, he arrived in the Emergency Department. Intravenous paraldehyde and a partial DPH loading dose finally stopped his seizures. Instead of awakening within 12 - 24 hours of cessation of convulsive status, as had been the case in the past, he was still unresponsive 36 hours later. At this time his blood urea nitrogen (BUN) was elevated (47 $\mathrm{mgm} \%)$; SGOT was greater than 4500 I.U.; $\mathrm{pH}$ 7.28; serum sodium was 129 $\mathrm{mEq} / \mathrm{L}$; and VPA serum level was 29 $\mathrm{ug} / \mathrm{ml}$. Urinalysis, complete blood count and other serum electrolytes were normal. An EEG done at this time showed generalized high voltage bursts of sharp/slow wave complexes lasting 2 to 5 seconds, intermixed with very low voltage theta runs lasting 5 to $10 \mathrm{se}$ conds. Because of the striking biochemical abnormalities, VPA and ethosuximide were stopped. Shifting multifocal seizures continued intermittently over the next 2 to 3 days. The patient continued to be responsive only to painful stimuli and showed no localizing neurological signs.

On day 3 he became unresponsive to painful stimuli. Fundus exam showed venous engorgement, oculocephalic reflexes were absent, and the limbs were flaccid. Intracranial pressure (ICP) monitoring was begun, with initial pressure at 66 Torr. The pressure elevation responded to the use of intermittent doses of mannitol, intubation, hyperventilation and hypothermia. At this time the serum ammonia level was 264, SGOT had fallen to 219 I.U., serum bilirubin remained normal, 


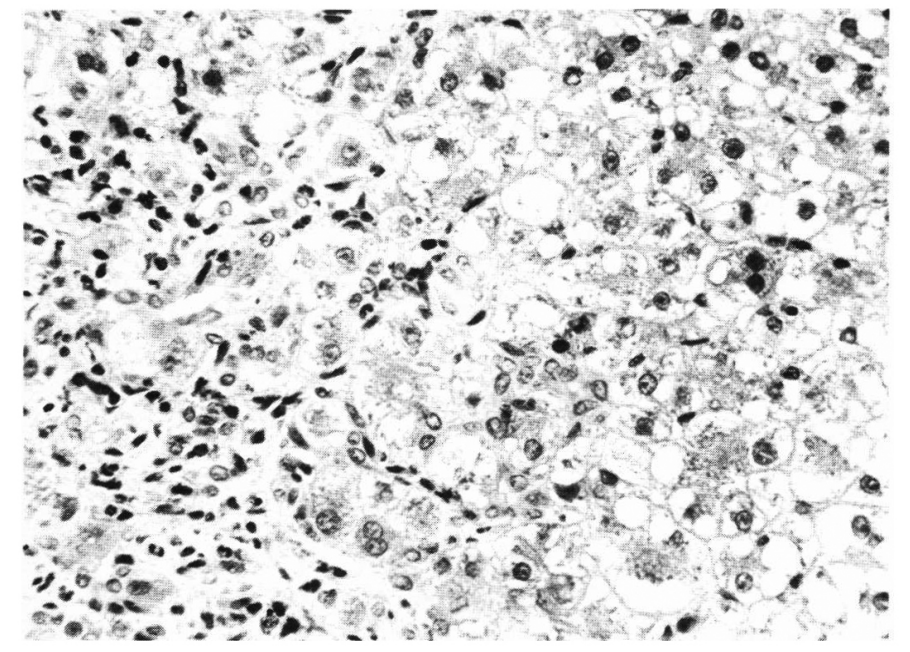

Figure I: Section showing disorganization, fatty infiltration and mononuclear infiltrate HPSx 300 .

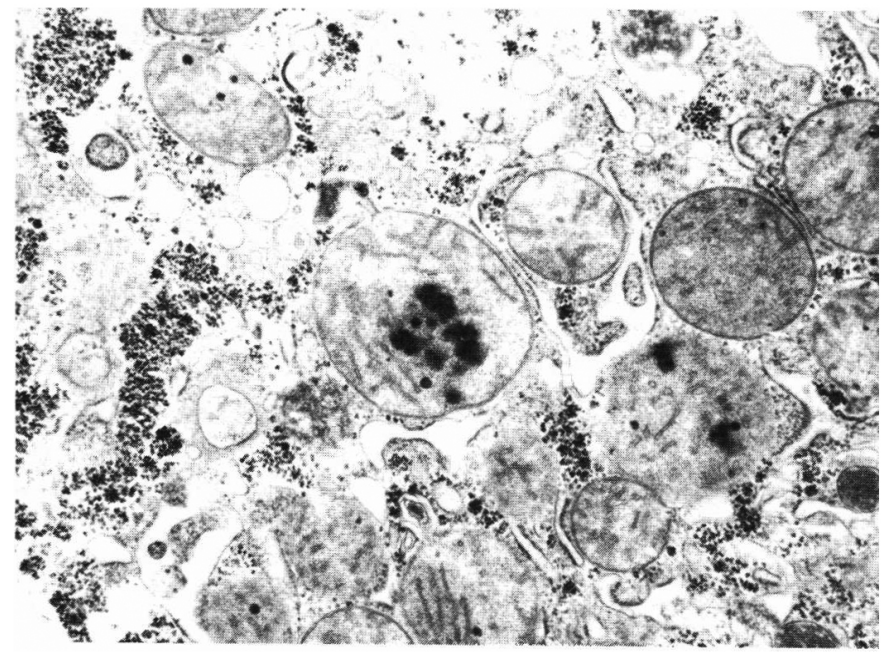

Figure II: Electron micrograph showing swollen mitochondria with disorganization of the cristae and accumulation of amorphous dense material EMx32000. prothrombin and partial thromboplastin times were elevated, BUN was $52 \mathrm{mgm} \%$ and creatinine 2.1 $\mathrm{mg} \%$. A repeat EEG showed a marked generalized suppression of background activity. Over the next 5 days his neurological status failed to improve and his liver began to enlarge. Liver biopsy done on day 10 showed widespread disorganization of the parenchyma with swelling of the hepatocytes and compression of the sinusoids. The normal trabecular pattern was blurred. There was a diffuse fatty infiltration including macrovacuoles as well as microvacuoles. Degenerative hepatic changes were present. Cholestasis was seen in the parenchyma. The portal triads showed portal fibrosis extending to the midzonal area. There was a moderate mononuclear cell infiltrate mainly in the portal triad extending into the sinusoid around the hepatocytes (Figure 1). Sections examined under electron microscopy showed reactive nuclei with prominent nucleoli in which there was a normal amount of glycogen. Multiple small fat droplets were seen pushing the organelles aside. The mitochondria were swollen and irregular in size, but the surrounding membranes were intact. The cristae were disorganized and some showed loss of granules. Other mitochondria showed accumulation of amorphous dense material (Figure 2).

Elevation of ICP persisted in spite of hyperventilation, hypothermia, decadron and intermittent use of mannitol. On day 13 barbiturate coma was started in an attempt to control the increasing elevation of ICP, unfortunately to no avail. He died on day 22 as a result of uncontrolled intracranial hypertension and resulting abolition of cerebral perfusion.

\section{DISCUSSION}

This case illustrates the most serious and uncommon form of hepatic dysfunction associated with VPA. The most common complication reported is elevation of SGOT values. Willmore et al (1978) reported that 4 of their 25 patients had elevated SGOT levels. These patients were on dosages of VPA ranging from 19 to $50 \mathrm{mg} / \mathrm{kg} / \mathrm{day}$, with an average daily dosage of $40.7 \mathrm{mg} / \mathrm{kg}$. All patients had been taking the drug for at least ten days prior to the SGOT elevation. With a reduction in the total daily dosage of VPA, SGOT levels returned to normal. These authors recommended decreasing the total dosage of VPA by $10 \mathrm{mg} / \mathrm{kg} / \mathrm{day}$ if SGOT levels became elevated. Vining et al (1979) and Sherrard et al (1980) also reported elevated SGOT levels in some of their patients on VPA, usually occurring between 10 and 20 weeks after starting the drug. Unlike Willmore et al, these authors found this to be a transient state which resolved spontaneously without any change in VPA dosage.
Several fatal cases of hepatic dysfunction associated with VPA usage have been reported (Abbott Laboratories personal communications; Addison et al, 1980; Browne et al, 1980; Donat et al, 1979; Gerber et al, 1979; Jacobi et al, 1980; Mounet et al, 1979; Sussman et al, 1979; Young et al, 1980; Ware et al, 1980). Some of these cases were similar to ours in that they involved children with major neurological handicaps on multiple anticonvulsant medications. In most of the reported cases the onset of hepatic dysfunction was within six months of starting the drug (unlike our case).

Clinically, the fatal cases of hepatic dysfunction associated with VPA can be divided into two groups: (1) a chronic progressive form and (2) an acute fulminating form. The chronic form is characterized by a four to six week course of slowly increasing lethargy, vomiting, nausea, anorexia, jaundice and edema. It occurs mostly in older patients. When VPA has been stopped early in the course of this slowly progressive form the patients have recovered. In cases where liver tissue has been studied the histology has been unimpressive except for cholestasis in a few cases.

The acute fulminating form of hepatic dysfunction, of which our patient was an example, usually occurs in children under twelve years of age. Onset of symptoms is typically sudden and without warning (i.e. abrupt onset 
of coma with signs of increased intracranial pressure). Jaundice is absent. Marked coagulation abnormalities and elevated SGOT and ammonia levels have been present in all cases at the time of onset of symptoms, but not before. Renal failure occurred in some patients. Liver biopsies have shown microvesicular fatty changes in the hepatocytes with mitochondrial dissolution. All the reported patients in this category have died.

There are many features of this acute fulminating form which are reminiscent of Reye's syndrome. Both are acute illnesses seen predominantly in childhood associated with multisystem metabolic failure, increased intracranial pressure and coma. Jaundice is absent. In both, liver biopsies show microvesicular fatty changes and mitochondrial dissolution in the hepatocytes. In Reye's syndrome the hepatic and cerebral symptoms are thought to result from sudden cessation of mitochondrial function in the liver and brain respectively (DeVivo, 1978).

There are interesting similarities between the chemical structure of VPA (2-n-propylpentanoic acid) and hypoglycin (the substance implicated in the Reye-like Jamaican vomiting sickness) and pentanoic acid (a potential inhibitor of fatty acid oxidation capable of inducing a Reye-like syndrome in dogs) (Trauner et al, 1975). All are short-chain fatty acids. Free fatty acid levels are characteristically elevated in Reye's syndrome although the relationship between this phenomenon and the development of mitochondrial failure is not known. Recent work by Haas et al (1981) has shown that VPA inhibits oxidative phosphorylation in isolated rat liver mitochondria. Thus, there is a possible link between acute VPA induced hepatic failure in man and the Reye-like syndrome induced in dogs by pentanoic acid and, by implication, the human Reye syndrome. It is our hypothesis that in some VPA-treated patients mitochondrial oxidative function is mildly impaired leading to transient elevations of SGOT and ammonia levels, which are reversed by stopping the drug or reducing its dosage. A few individuals develop chronic progressive hepatic dysfunction, which if left undetected goes on to irreversible hepatic failure. A few unfortunate patients will suddenly develop acute generalized mitochondrial decompensation resulting in hepatic failure, cerebral edema, coma and death. It is not possible to predict which form will occur in which patient, although the chronic and acute types of hepatic failure tend to affect different age groups. These differences in mitochondrial response to VPA may occur because of (1) the co-existence in severe cases of other predisposing factors such as inborn partial deficiencies of critical mitochondrial enzymes (e.g. carbamyl phosphate synthetase, pyruvate dehydrogenase complex, etc.), (2) the added stress of an acute viral ilIness or (3) concomitant use of other drugs metabolized by mitochondrial enzyme systems.

Our experience with this case has led us to consider the following recommendations:

1. Routine determination of $\mathrm{CBC}$, SGOT and platelets in patients on VPA should be done at 6 weeks, 3 months and 6 months after starting the drug, and thereafter at 6 month intervals as long as the drug is taken.

2. Until more data are available, patients on VPA with elevated SGOT levels should have their VPA dosage reduced as recommended by Willmore et al (1978).

3. Until more data are available, children on VPA who develop an acute Reye-like syndrome should be managed aggressively as if they had Reye's syndrome (Trauner, 1980), and VPA should be discontinued immediately.

\section{REFERENCES}

ADDISON, G.M. AND GORDAN, N.S. (1980). Sodium Valproate and Acute Hepatic Failure. Dev. Med. Child. Neurol. 22:248-249.

BROWNE, T R. (1980). Drug Therapy - Valproic Acid. N. Eng. J. Med. Vol. 302:661666.

DEVIVO, D.C. (1978). Reye Syndrome - A Metabolic Response to An Acute Mitochondrial Insult? Neurol. 28:105-108.

DONAT, J.; BOCCHINI, J.; GONZALEZ, E. AND SCHWENDIMANN, R. N. (1979). Valproic Acid and Fatal Hepatitis. Neurol. 29: 273-274.
GERBER, N.; DICKINSON, R.G.; HARLAND, R.C.; LYNN, R.K.; HOUGHTON, D.; ANTONIAS, J.L.; AND SCHIMSCHOCK, J.C. (1979). ReyeLike Syndrome Associated with Valproic Acid Therapy.J. Peds. 95:142-144.

HAAS, R.; STUMPF, D.A.; PARKS, J.K.; AND EGUREN, L. (1981). Inhibitory Effects of Sodium Valproate on Oxidative Phosphorylation. Neurol. 31:1473-1476.

JACOBI, G.; THURBECK, R.; RITZ, A.; JANSSEN, W. AND SCHMIDTS, $H$. (1980). Fatal hepatotoxicity in Child on Phenobarbitone and Sodium Valproate. Lancet 1:712-714.

LUTHER, R.; - Abbott Laboratories - personal communications.

MONNET, P.; DAVID, M.; PHILLIPPE, N.; DECHAUANNE, M.; FLORET, D. RENAUD, H.; TREZECIAK, M.C.; BRAZIER, J.L. AND BOURDILLON, D. (1979). Changes of Hemostasis During Treatment with Sodium Dipropylacetate (Depakene). Pediatrics 24:603-620.

SHERARD, E.; STEINMAN, G.S.; AND COUN, D. (1980). Treatment of Childhood Epilepsy with Valproic Acid: Results of the First 100 Patients in a 6-Month trial. Neurol. 30:31-35.

SUCHY, F.; BALISTRERI, W.; BUCHINO. J.; SONDHEIMER, J.; BATES, S.; KEARNS, G.L.; STULL, J.D.; AND BOVE, K. (1979). Acute Hepatic Failure Associated with the Use of Sodium Valproate. N. Eng. J. Med. 300:962-966.

SUSSMAN, N.; AND McLAIN, W. (1979). A Direct Hepatotoxic Effect of Valproic Acid. J.A.M.A. 242-1173-1174.

TRAUNER, D.A. (1980). Treatment of Reye's Syndrome. Ann. Neurol. 7:2-4.

TRAUNER, D.A.; MYHAM, W.L.; SWEETMAN, L. (1975). Short-Chain Organic Acidemia and Reye's Syndrome. Neurol. 25:296-298.

VINING, E.P.G.; BOTSFORD, E.; AND FREEMAN, J.M. (1979). Valproate Sodium in Refractory Seizures. Am. J. Dis Child 133:274-276.

WARE, S.; AND MILLWARD-SADLER, G.H. (1980). Acute Liver Disease Associated with Sodium Valproate. Ann. Neuro. 7:1110-1113.

WILLMORE, L.J.; WILDER, B.J.; BRUNI, J. AND VILLAREAL, H.J. (1978). Effect of Valproic Acid on Hepatic Functions. Neurol. 28:961-964.

YOUNG, R.S.; BERGMAN, I.; GANG, D.L.; AND RICHARDSON, E. (1980). Fatal Reye-Like Syndrome Associated with Valproic Acid. Amn. Neurol. Vol. 7:389. 